\title{
Hemodynamic monitoring in Nigerian patients undergoing high-risk surgery
}

\author{
Babatunde Babasola Osinaike ${ }^{1,2}$
}

Background: Hemodynamic monitoring (HM) and optimization of cardiac output and parameters of dynamic fluid responsiveness is said to improve perioperative outcome in high-risk surgical patients (HRSP). There is insufficient data to determine the burden of care and HM practices in HRSP in Nigeria. Hence, the need to assess and document the current hemodynamic management practices of anesthetists in Nigeria regarding patients undergoing high-risk surgery. Methods: An electronic mail (E-mail) based survey was conducted among 180 consultant members of the Nigeria Society of Anaesthetists. The survey contained 24 questions that range from practice location, experience in the perioperative management of high-risk patients, expectations of care, to what is available to the anesthetists to provide such care. The survey was on for 3 months. Results: A total of $157 \mathrm{E}$-mail messages were delivered, and 73 responses were received, giving a response rate of $46.5 \%$. The survey showed that 67 (91.8\%) of respondents provide or directly supervise anesthesia for HRSP, 50 (84\%) of them do this I-5 times a week. Noninvasive blood pressure $(83.6 \%)$ was routinely monitored while the central venous pressure (CVP 35.6\%), invasive blood pressure (28.8\%), and cardiac output (I.4\%) monitored less often. Urine output, arterial blood pressure, pulse rate, and clinical experience were considered best indicators of volume expansion. Most respondents were of the opinion that oxygen delivery to tissues is of major importance during the management of HRSP. Conclusion: Nigerian consultant anesthetists employ mostly noninvasive blood pressure, CVP, and invasive blood pressure for HM in HRSP.Though a good knowledge of hemodynamic goals was demonstrated, most rated their practice as inadequate.

Keywords: Hemodynamics, high-risk surgery, monitoring, Nigeria

\section{Introduction}

The management of high-risk surgical patients (HRSP) presents a huge challenge to anesthetist as a perioperative physician. Often, there is a need to balance on one hand the provision of a good anesthesia that prevents undue stimulation of sympathetic responses/reflexes and then tilting the already deranged hemodynamics off balance. Invasive or noninvasive hemodynamic monitoring (HM) offers the anesthetist the opportunity to walk on this

From:

${ }^{1}$ Department of Anaesthesia, University College Hospital, Ibadan,

${ }^{2}$ Department of Anaesthesia, College of Medicine, University of Ibadan, Ibadan,

Oyo State, Nigeria

Correspondence:

Dr. Babatunde Babasola Osinaike, Department of Anaesthesia,

University College Hospital, PMB 5116, Dugbe, Ibadan, Oyo State, Nigeria.

E-mail: drosinaike@yahoo.co.uk

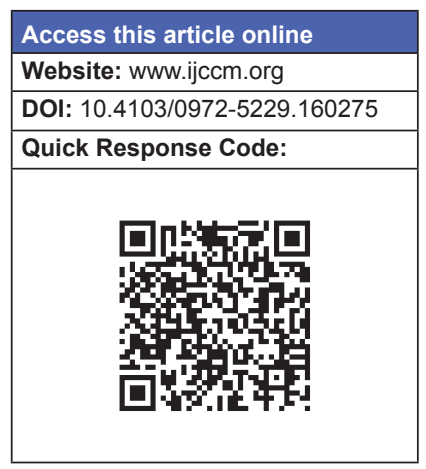

"tightrope" successfully most times. In the United Kingdom, surgical procedures involving high-risk patients is said to represent only about $10 \%$ of the procedures anesthetists perform each year, yet these patients account for over $80 \%$ of perioperative deaths. ${ }^{[1]}$ This is a pointer to the need for a closer attention to this subset of surgical patients. Unfortunately, there is insufficient data to determine the burden of care and outcome in HRSP in Nigeria.

This is an open access article distributed under the terms of the Creative Commons Attribution-NonCommercial-ShareAlike 3.0 License, which allows others to remix, tweak, and build upon the work non-commercially, as long as the author is credited and the new creations are licensed under the identical terms.

For reprints contact: reprints@ medknow.com

How to cite this article: Osinaike BB. Hemodynamic monitoring in Nigerian patients undergoing high-risk surgery. Indian J Crit Care Med 2015;19:388-93. 
A similar survey conducted among randomly selected European and American anesthetists showed that having adequate physiological knowledge of $\mathrm{HM}$ is not directly related to application of such knowledge during patient care and that "clinical practice may be heavily influenced by local factors that may not be justified by basic physiological considerations and the published body of evidence."[2]

In light of the above, it became necessary to assess and document the current hemodynamic management practices of anesthetists in Nigeria regarding patients undergoing high-risk surgery.

\section{Methods}

An electronic mail (E-mail) based survey was conducted among consultant anesthetists in Nigeria. The membership strength of the Nigerian Society of Anaesthetists (NSA) is about 650, with consultants making up a quarter; others include medical officers with diploma and resident doctors. Permission was obtained to use the E-mail addresses of all consultant anesthetists in the directory (180 members) for this survey.

The survey contained 24 questions adapted from a similar study ${ }^{[2]}$ that range from practice location, experience in the perioperative management of $\mathrm{HR}$ patients, expectations of care, to what is available to the anesthetists to provide such care. The survey was on for 3 months with weekly reminders sent to participants to enhance the response rate.

The definition for HRSP in this study followed that by Shoemaker et al.,$^{[3]}$ as those presenting for major surgery expected to last more than $1.5 \mathrm{~h}$ and having at least two of the following criteria: Previous severe cardio-respiratory illness-acute myocardial infarction, chronic obstructive pulmonary disease/stroke, late-stage vascular disease involving aorta, Age $>70$ years with limited physiological reserve in one or more vital organs, extensive surgery for carcinoma (e.g., esophagectomy, gastrectomy, cystectomy), acute abdominal catastrophe with hemodynamic instability (e.g., peritonitis, perforated viscus, pancreatitis), acute massive blood loss $>8$ units, septicemia positive blood culture or septic focus, respiratory failure: $\mathrm{PaO}_{2}<8.0 \mathrm{kPa}$ on $\mathrm{FIO}_{2}>0.4$ or mechanical ventilation $>48 \mathrm{~h}$, acute renal failure: Urea $>20 \mathrm{mmol} / 1$ or creatinine $>260 \mathrm{mmol} / 1$.

\section{Statistical analysis}

Data were entered into the Statistical Package of Social Sciences (SPSS) version 17.0 Chicago, Illinois, USA. Since the data were mainly categorical, they were expressed as counts/percentages and subjected to Chi-square analysis. Linear regression was done as required. $P<0.05$ was regarded as significant.

\section{Results}

Of the 180 consultant members of the NSA contacted, only 157 E-mail messages were delivered. Twenty-one messages were undelivered, and 2 persons opted out of the survey without reasons. We received 73 responses, giving a response rate of $46.5 \%$.

The survey showed that 67 (91.8\%) of respondents provide or directly supervise anesthesia for HRSP, $50(84 \%)$ of them do this $1-5$ times a week. Furthermore, $27(40.3 \%)$ and $38(56.7 \%)$ of them have been practicing as anesthetists for 5-10 years and above 10 years, respectively. Most respondents in this survey work in the University Teaching Hospital 52 (71.2\%) with the location of practice in the South West 25 (34.2\%) [Table 1]. Thirty-four (46.5\%) of our respondents have additional fellowship. The most frequent fellowship was critical care $(19 \%)$, followed by pain $(11 \%)$ and cardiac anesthesia $(9.5 \%)$.

Most respondents 60 (83\%) admitted that no formal guidelines for the management of HRSP existed in their institutions [Figure 1]. Table 2 shows that most of our respondents routinely monitor noninvasive blood pressure monitoring $(83.6 \%)$, central venous (35.6\%), and

\begin{tabular}{|c|c|}
\hline & Frequency of responses $n(\%)$ \\
\hline \multicolumn{2}{|c|}{ Provide or directly supervise } \\
\hline \multicolumn{2}{|c|}{ anesthesia for this high-risk patient } \\
\hline Yes & $67(91.8)$ \\
\hline No & $3(4.1)$ \\
\hline No response & $3(4.1)$ \\
\hline \multicolumn{2}{|c|}{$\begin{array}{l}\text { Duration of practice as consultant } \\
\text { anaesthetist }\end{array}$} \\
\hline$<5$ years & $3(4.1)$ \\
\hline $5-10$ years & $27(37.1)$ \\
\hline Above 10 years & $4 \mathrm{I}(56.2)$ \\
\hline No response & $2(2.7)$ \\
\hline \multicolumn{2}{|l|}{ Practice setting } \\
\hline University hospital & $54(74.0)$ \\
\hline General hospital & $3(4.1)$ \\
\hline Private practice & $2(2.2)$ \\
\hline Other & $14(19.2)$ \\
\hline \multicolumn{2}{|l|}{ Practice location } \\
\hline South West & $25(34.2)$ \\
\hline South East & II (15.I) \\
\hline South-South & $12(16.4)$ \\
\hline North West & $17(9.6)$ \\
\hline North East & $2(2.7)$ \\
\hline North Central & $7(9.6)$ \\
\hline Abuja & $3(4.1)$ \\
\hline No response & $6(8.2)$ \\
\hline
\end{tabular}


Table 2: Frequency of hemodynamic monitoring used during high-risk surgery in the current and previous surveys

\begin{tabular}{|c|c|c|c|c|c|}
\hline \multirow[t]{2}{*}{ Options } & \multicolumn{5}{|c|}{ Response percentage } \\
\hline & NSA $(n=73)$ & $\mathrm{KSA}^{[4]}(n=72)$ & $\operatorname{CSA}^{[5]}(n=2 \mid 0)$ & $\operatorname{ESA}^{[2]}(n=162)$ & $\operatorname{ASA}^{[2]}(n=203)$ \\
\hline Noninvasive arterial pressure & 83.6 & 64.2 & 66.7 & 89.7 & 51.9 \\
\hline Central venous pressure & 35.6 & 93.4 & 82.9 & 83.6 & 72.6 \\
\hline Invasive arterial pressure & 28.8 & 97.2 & 91.4 & 89.7 & 95.4 \\
\hline Mixed venous saturation & 1.4 & 18.9 & 14.3 & 15.9 & 14.3 \\
\hline Transesophageal echocardiography & $\mathrm{I} .4$ & 31.1 & 13.3 & 19.0 & 28.3 \\
\hline Cardiac output & 1.4 & 58.5 & 13.3 & 34.9 & 35.4 \\
\hline Central venous saturation & 0 & 24.5 & 10.5 & 33.3 & 12.7 \\
\hline Pulmonary capillary wedge pressure & 0 & 25.5 & 11.4 & 14.4 & 30.8 \\
\hline Pulse pressure variation & 0 & 29.2 & 1.9 & 23.6 & 15.2 \\
\hline Systolic pressure variation & 0 & 28.3 & 1.9 & 23.6 & 15.2 \\
\hline
\end{tabular}

NSA: Nigerian Society of Anaesthetists; CSA: China Society of Anesthesiologists; KSA: Korean Society of Anesthesiologists; ASA: American Society of Anesthesiologists; ESA: European Society of Anaesthesiologists

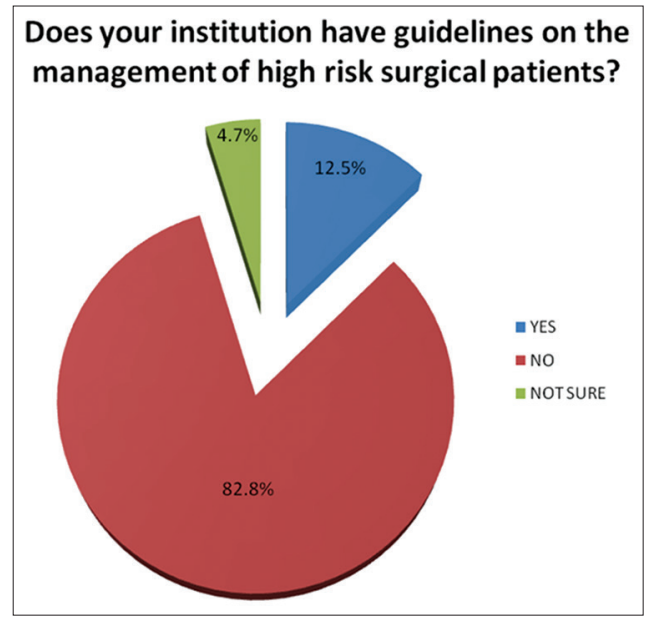

Figure I: Pie chart showing availability of guidelines for the management of high-risk surgical patients in respondent's institution

invasive arterial blood pressure (28.8\%) during surgery in HRSP. It also compared our data with that of four similar surveys.

The practice setting $(P=0.129)$, presence of institutional guidelines $(P=0.277)$, and possession of additional fellowship $(P=0.108)$ did not influence the choice of noninvasive blood pressure, central venous pressure (CVP), and invasive arterial blood pressure use as HM devices. However, the duration $(P=0.023)$ and location of practice $(P=0.048)$ were significantly related to the use of invasive blood pressure monitoring with more respondents with duration of practice over 5 years and location of practice in the south west employing invasive blood pressure monitoring.

Three times more respondents will employ arterial pressure rather than venous pressure monitoring to optimize the hemodynamics $75 \%$ of the time intraoperatively [Figure 2]. The responses to the questions on indicators of volume expansion, their opinion on what predicts increase in cardiac output

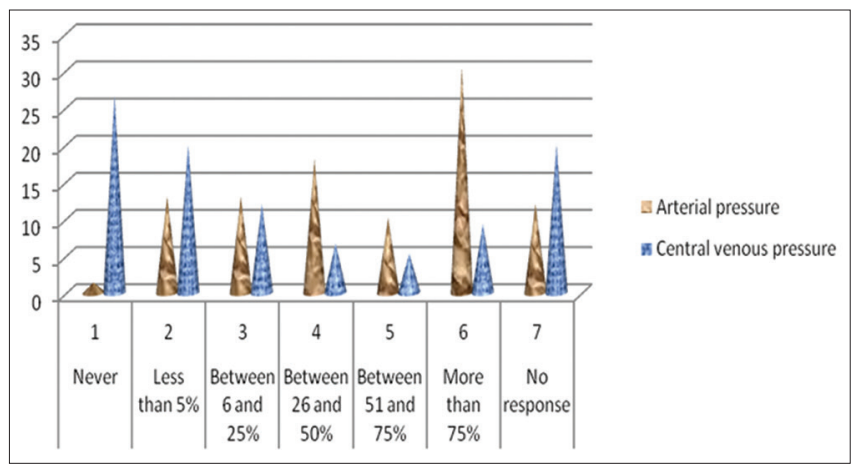

Figure 2: Frequency of optimization of arterial and central venous pressure intraoperatively

after volume expansion and parameters involved in oxygen delivery to tissues are shown in Tables 3,4 , and 5 respectively.

A large number of our respondents 65 (83.3\%) were of the opinion that oxygen delivery to tissues is of major importance during the management of HRSP and the following parameters are important for oxygen delivery; cardiac output $(75.6 \%)$, hemoglobin concentration $(74.4 \%)$, and partial pressure of oxygen $(66.7 \%)$ [Table 5].

Most respondents (73.9\%) will optimize patients before induction of anesthesia, and most of them are of the opinion that this period is of utmost value to achieve hemodynamic optimization. Considering the first choice solution for volume expansion, crystalloids, and hydroxyl ethyl starch (HES) were the first choice in $46(63.0 \%)$ and $10(14.0 \%)$ of respondents respectively.

About two-third of our respondents 41 (59.41\%) believe that their current practice of intraoperative hemodynamic management of the high-risk patient is inadequate. This included $60 \%$ of those with additional training. No difference was found between respondents with 


\begin{tabular}{lc}
\hline Table 3: Indicators of volume expansion & \\
\hline Parameters & Percentage \\
\hline Urine output & 82.2 \\
Arterial blood pressure & 78.1 \\
Pulse rate & 74.0 \\
Clinical experience & 52.1 \\
Plethysmography waveform & 50.7 \\
Central venous pressure & 41.1 \\
Blood loss & 2.8 \\
Capillary refill & 1.4 \\
Difference between peripheral core temperature & 1.4 \\
\hline
\end{tabular}

Table 4: Physician opinions on predictors of increase in Cardiac Output after volume expansion

\begin{tabular}{lc}
\hline Parameters & Percentage \\
\hline Arterial blood pressure & 53.4 \\
Central venous pressure & 45.2 \\
Transesophageal echocardiography & 27.4 \\
Pulmonary capillary wedge pressure & 24.7 \\
Plethysmography waveform & 23.3 \\
Clinical experience & 23.3 \\
Mixed venous oxygen saturation $\left(\mathrm{ScvO}_{2}\right)$ & 13.7 \\
Central venous oxygen saturation $\left(\mathrm{SvO}_{2}\right)$ & 6.8 \\
\hline
\end{tabular}

Table 5: Physician opinions as indicators of oxygen delivery

\begin{tabular}{lc}
\hline Parameters & Percentage \\
\hline Cardiac output & 75.6 \\
Hemoglobin & 74.4 \\
Partial pressure of oxygen & 66.7 \\
Oxygen saturation & 55.1 \\
Arterial pressure & 42.3 \\
Central venous pressure & 14.1 \\
\hline
\end{tabular}

additional training and those without with regard to their opinion on the adequacy of current practice $(P=0.299)$.

\section{Discussion}

This survey revealed that most of our respondents are involved in the perioperative care of HRSP even without institutional guidelines or protocol for the management of such patients. We also observed the noninvasive blood pressure to be the most common parameter used for $\mathrm{HM}$, with CVP, and invasive blood pressure monitoring in distant second and third positions. Majority of our respondents work in University Teaching Hospitals, the consensus is that monitoring oxygen delivery in HRSP remains a major goal and cardiac output monitoring, hemoglobin assessment and partial pressure of oxygen assessment are important parameters involved.

The goals of HM are essentially to guarantee the adequacy of perfusion, assist with early detection of inadequate perfusion so as to guide decision making on whether monitoring is sufficient or not, or if the patient need active intervention. Others include titrating the therapy to specific hemodynamic endpoints in unstable patients and differentiating among various organ system dysfunctions. It is, therefore, important that clinical audit or surveys of this type be conducted from time to time to determine if expected goals are being achieved.

Despite the fact that most of the respondents are of the opinion that oxygen delivery to tissues are of major importance during management of HRSP and that cardiac output presents a very good tool to monitor this compared to CVP, more respondents employ CVP monitoring than routine cardiac output assessment or other parameters involved in oxygen delivery in HRSP. In agreement with a similar study,,$^{[2]}$ there appears to be a gap between the knowledge and practice with regard to routine monitoring devices employed by respondents in this study.

Though this result agrees with that obtained in similar studies conducted among Korean, Chinese, American, and European anesthetists, ${ }^{[2,4,6]}$ we observed a huge gap in the usage of these two monitoring devices in this survey. The reasons responsible for low application of the cardiac output monitoring in other studies include the fact that some believe that cardiac output maximization is unnecessary or may be harmful ${ }^{[7,8]}$ and that the procedure is difficult to perform routinely in the busy operating room. However, the reason for this gap in our environment is majorly the unavailability of these tools because of the high cost. Poor funding of health care in general and particularly critical care services remain one of the reasons responsible for inadequate provision of basic monitoring devices and more advanced ones such as the cardiac output monitors, arterial blood gas machines, transesophageal echocardiography, etc. Even when the facility is available, the prohibitive cost makes it unaffordable for an average patient.

Despite the infrequent use of the venous pressure for optimization of hemodynamics among our respondents, the use of CVP monitoring featured prominently as HM tool. This "addiction" to CVP by many clinicians despite studies that have shown its inadequate predictability of fluid responsiveness ${ }^{[5,9]}$ has been documented by many other authors. ${ }^{[2,4,6]}$ This has been attributed to familiarity with traditional variables and unavailability of standard protocols for cardiac output optimization. ${ }^{[4]}$ Considering available HM tools available in Nigeria, central venous monitoring appears to be an important tool and may represent the peak device for assessing fluid responsiveness among high-risk patients. More recent parameters such as pulse pressure variation and systolic pressure variation are said to provide more 
reliable information about fluid responsiveness ${ }^{[10,11]}$ and can be employed readily. Acquiring equipment that provides real-time values of these parameters may be a challenge for poor resource economy like ours, however, the parameters can be calculated intermittently at bedside from information obtained from the invasive arterial pressure waveform. ${ }^{[12]}$

As opined by most respondents in this survey, hemoglobin assessment is a useful way of monitoring oxygen delivery. This, however, does not suggest improved oxygen delivery with higher hemoglobin levels. Results of recent studies did not show improved outcome in HRSP and critically ill patients following liberal transfusion compared to restrictive blood transfusion. ${ }^{[13,14]}$

The choice of crystalloids as first choice fluid for resuscitation by most of our respondents agrees with the opinion of American anesthetists in a similar study ${ }^{[2]}$ but differs from that of European and Chinese anesthetists. ${ }^{[2,5]}$ The availability and lower cost of crystalloids could have played a role. While the controversy surrounding the choice of the best fluid for resuscitation rages on, many authors ${ }^{[13-17]}$ continue to report on the limitations of crystalloids use.

Nunes et al..$^{[15]}$ in their study on the hemodynamic effects of crystalloids of patients with circulatory shock observed that cardiac index decreased toward baseline values $60 \mathrm{~min}$ after crystalloid infusion. This further strengthens the body of evidence that the hemodynamic effect of volume expansion with crystalloid is short. Reasons that have been adduced to be responsible for this includes the limited intravascular volume effect of crystalloids revealed by volume kinetics studies ${ }^{[16,17]}$ and damage to the endothelial glycocalyx layer under inflammatory conditions such as sepsis, surgery or trauma leading to protein extravasation, and reduced intravascular effect of crystalloids. ${ }^{[18,19]}$

Some of our respondents will prefer HES as a first line product. Though the use of HES helps with the reduction of resuscitation fluid volume, it is currently the subject of many trials trying to assess its safety. In studies involving a patient with severe sepsis, HES was associated with increased mortality and acute kidney injury resulting in the need for renal-replacement therapy. ${ }^{[2,21]}$

With almost half of our respondents possessing additional fellowship especially in critical care and cardiac anesthesia, the inability to constantly employ their skill may lead to skill attrition and frustration especially when they lack materials and equipment needed to provide standard care despite having adequate knowledge of what to do. Anesthetists managing HRSP in our environment appear gravely constraint and are therefore left with basic monitoring tools for noninvasive blood pressure, electrocardiograph, oxygen saturation, and end-tidal carbon dioxide which are insufficient for high-risk patients and early goal directed therapy.

It has been said that "no monitoring tool, no matter how accurate, by itself has improved patient outcome."[22] While attempts are on in improving access to new technologies to improve the level of monitoring available for HRSP, clinicians must ensure judicious use of available devices in the best way possible to reduce the morbidity and mortality in this group of patients.

The response rate of $46.5 \%$ is the main limitation of this study. This is, however, higher than that obtained from the ASA members (42.9\%) and close to that of the ESA members $(57.1 \%)$ in a similar study. ${ }^{[2]}$ Inadequate access to internet and use of wrong E-mail addresses played major roles in this low response rate. Furthermore, there is a possibility that some of the anesthetists contacted may be uninterested in the survey because of little or no involvement in the care of HRSP.

\section{Conclusion}

Nigerian consultant anesthetists employ mostly noninvasive blood pressure, CVP, and invasive blood pressure for HM in HRSP. They demonstrated a good knowledge of necessary hemodynamic goals to achieve during management of HRSP. However, most rated their current practice as inadequate largely because of unavailability of better HM and other tools for monitoring oxygen delivery during surgery for high-risk patients. A prospective observational study is needed to assess outcome in this subset of Nigerian patients.

\section{Acknowledgment}

The support of the NSA is highly appreciated.

\section{Financial support and sponsorship}

Nil.

\section{Conflicts of interest}

There are no conflicts of interest.

\section{References}

1. Pearse RM, Harrison DA, James P, Watson D, Hinds C, Rhodes A, et al. Identification and characterisation of the high-risk surgical population in the United Kingdom. Crit Care 2006;10:R81.

2. Cannesson M, Pestel G, Ricks C, Hoeft A, Perel A. Hemodynamic 
monitoring and management in patients undergoing high risk surgerv: A survey among North American and European anesthesiologists. Crit Care 2011;15:R197.

3. Shoemaker WC, Appel PL, Kram HB, Waxman K, Lee TS. Prospective trial of supranormal values of survivors as therapeutic goals in high-risk surgical patients. Chest 1988;94:1176-86.

4. Kim SH, Kim MJ, Lee JH, Cho SH, Chae WS, Cannesson M. Current practice in hemodynamic monitoring and management in high-risk surgery patients: A national survey of Korean anesthesiologists. Korean J Anesthesiol 2013;65:19-32.

5. Osman D, Ridel C, Ray P, Monnet X, Anguel N, Richard C, et al. Cardiac filling pressures are not appropriate to predict hemodynamic response to volume challenge. Crit Care Med 2007;35:64-8.

6. Chen G, Zuo Y, Yang L, Chung E, Cannesson M. Hemodynamic monitoring and management of patients undergoing high-risk surgery: A survey among Chinese anesthesiologists. J Biomed Res 2014;28:376-82

7. Hayes MA, Timmins AC, Yau EH, Palazzo M, Hinds CJ, Watson D. Elevation of systemic oxygen delivery in the treatment of critically ill patients. N Engl J Med 1994;330:1717-22

8. Gattinoni L, Brazzi L, Pelosi P, Latini R, Tognoni G, Pesenti A, et al. A trial of goal-oriented hemodynamic therapy in critically ill patients. SvO, Collaborative Group. N Engl J Med 1995;333:1025-32.

9. Marik PE, Baram M, Vahid B. Does central venous pressure predict fluid responsiveness? A systematic review of the literature and the tale of seven mares. Chest 2008;134:172-8.

10. Lopes MR, Oliveira MA, Pereira VO, Lemos IP, Auler JO Jr, Michard F. Goal-directed fluid management based on pulse pressure variation monitoring during high-risk surgery: A pilot randomized controlled trial. Crit Care 2007;11:R100.

11. Mayer J, Boldt J, Mengistu AM, Röhm KD, Suttner S. Goal-directed intraoperative therapy based on autocalibrated arterial pressure waveform analysis reduces hospital stav in high-risk surgical patients:
A randomized, controlled trial. Crit Care 2010;14:R18.

12. Bridges E. Using functional hemodynamic indicators to guide fluid therapy. Am J Nurs 2013;113:42-50.

13. ProCESS Investigators, Yealy DM, Kellum JA, Huang DT, Barnato AE, Weissfeld LA, et al. A randomized trial of protocol-based care for early septic shock. N Engl J Med 2014;370:1683-93.

14. Holst LB, Haase N, Wetterslev J, Wernerman J, Guttormsen AB, Karlsson S, et al. Lower versus higher hemoglobin threshold for transfusion in septic shock. N Engl J Med 2014;371:1381-91.

15. Nunes TS, Ladeira RT, Bafi AT, de Azevedo LC, Machado FR, Freitas FG. Duration of hemodynamic effects of crystalloids in patients with circulatory shock after initial resuscitation. Ann Intensive Care 2014;4:25.

16. Hahn RG. Volume kinetics for infusion fluids. Anesthesiology 2010;113:470-81.

17. McIlroy DR, Kharasch ED. Acute intravascular volume expansion with rapidly administered crystalloid or colloid in the setting of moderate hypovolemia. Anesth Analg 2003;96:1572-7.

18. Myburgh JA, Mythen MG. Resuscitation fluids. N Engl J Med 2013;369:2462-3.

19. Woodcock TE, Woodcock TM. Revised Starling equation and the glycocalyx model of transvascular fluid exchange: An improved paradigm for prescribing intravenous fluid therapy. $\mathrm{Br} \mathrm{J}$ Anaesth 2012;108:384-94.

20. Brunkhorst FM, Engel C, Bloos F, Meier-Hellmann A, Ragaller M, Weiler $\mathrm{N}$, et al. Intensive insulin therapy and pentastarch resuscitation in severe sepsis. N Engl J Med 2008;358:125-39.

21. Perner A, Haase N, Guttormsen AB, Tenhunen J, Klemenzson G, Åneman A, et al. Hydroxyethyl starch 130/0.42 versus Ringer's acetate in severe sepsis. N Engl .J Med 2012;367:124-34.

22. Pinsky MR. Hemodynamic monitoring over the past 10 years. Crit Care $2006 ; 10: 117$ 